\title{
Incidence and Etiology of Acute Kidney Injury in Southern India: Author's Reply
}

\author{
Sriram Krishnamurthy
}

Received: 15 April 2013 / Accepted: 16 April 2013 / Published online: 5 June 2013

(C) Dr. K C Chaudhuri Foundation 2013

To the Editor: Tropical acute febrile illnesses have been described as important causes of acute kidney injury (AKI) in developing countries [1-4]. There is renewal of interest with emergence of such diseases in the developed countries and non-tropical regions as well, due to global warming and travel to tropics [5].

In a study on 367 consecutively enrolled adult inpatients of a tertiary hospital in southern India, with tropical acute febrile illness due to scrub typhus, malaria, enteric fever, dengue, leptospirosis and undifferentiated acute febrile illness, the incidence of AKI was $41.1 \%$ [1]. Scrub typhus accounted for the majority (51.2\%) of tropical acute febrile illnesses in this study. The authors had opined that since a large number of patients with AKI in febrile illnesses in tropics have no access to medical attention or reside far away from large hospitals, they are likely to succumb to complications, making this a major public health concern.

In our study [6], tropical febrile illnesses accounted for $15.6 \%$ of all children with AKI. Severe dengue constituted the largest proportion of this group (38.4\%), while scrub typhus, enteric fever and cholera together accounted for $46.1 \%$. These figures are indeed considerably high, and call for attention from the general practitioner. Early detection of AKI in tropical febrile illnesses, which are very commonly prevalent in developing countries, is important for commencement of preventive strategies including judicious usage of fluids and adjustment of antibiotic doses, as well as identifying patients early to avoid renal replacement therapy. It therefore seems to be prudent to investigate renal functions in pediatric patients with tropical febrile illnesses. This practice needs to be included into clinical practice guidelines for management of tropical febrile illnesses.

\section{References}

1. Basu G, Chrispal A, Boorugu H, et al. Acute kidney injury in tropical acute febrile illness in a tertiary care centre-RIFLE criteria validation. Nephrol Dial Transplant. 2011;26:524-31.

2. Jha V, Chugh KS. Community-acquired acute kidney injury in Asia. Semin Nephrol. 2008;28:330-47.

3. Naicker S, Aboud O, Gharbi MB. Epidemiology of acute kidney injury in Africa. Semin Nephrol. 2008;28:348-53.

4. Sakhuja V, Sud K. Acute renal failure in the tropics. Saudi J Kidney Dis Transpl. 1998;9:247-60.

5. Wilson ME, Freedman DO. Etiology of travel-related fever. Curr Opin Infect Dis. 2007;20:449-53.

6. Krishnamurthy S, Mondal N, Narayanan P, Biswal N, Srinivasan S, Soundravally R. Incidence and etiology of acute kidney injury in Southern India. Indian J Pediatr. 2012; doi:10.1007/s12098-012-0791-z.
S. Krishnamurthy $(\bowtie)$

Department of Pediatrics, Jawaharlal Institute of Postgraduate

Medical Education and Research (JIPMER),

Pondicherry 605006, India

e-mail: drsriramk@yahoo.com 